\title{
Geographical range expansion of alien birds and environmental matching
}

\author{
SHAN SU, ${ }^{1,2}$ PHILLIP CASSEY, ${ }^{3}$ ELLIE E. DYER ${ }^{1,2} \&$ TIM M. BLACKBURN ${ }^{2,3,4 \star}$ \\ ${ }^{1}$ Institute of Zoology, Zoological Society of London, Regent's Park, London NW1 4RY, UK \\ ${ }^{2}$ Department of Genetics, Evolution and Environment, University College London, Gower Street, \\ London WC1E 6BT, UK \\ ${ }^{3}$ School of Biological Sciences, University of Adelaide, Adelaide, SA 5005, Australia \\ ${ }^{4}$ Centre for Invasion Biology, Department of Botany and Zoology, Stellenbosch University, Stellenbosch, South Africa
}

The international wildlife trade is a significant source of introduced alien species, some of which proceed to become invasive and cause negative environmental and economic effects. However, not all introduced aliens establish viable populations, and it is important to identify the factors that determine establishment success. We explore the role of environmental suitability (including anthropogenic influences, climate and habitat types) in the establishment success of alien bird species introduced to Taiwan. Using maximum entropy modelling, we employed a recursive feature elimination and Akaike information criterion (AIC)-based stepwise model selection approach to assess whether the environmental suitability, native range size, body size, residence time and the numbers of birds for sale in the shops affect variation in the extent of alien bird range size in Taiwan. We show that species with larger native range sizes and larger body sizes tend to have larger alien range sizes in Taiwan. There was no effect of environmental suitability on alien range size in Taiwan, but environmental suitability influenced the establishment success of bird species there.

Keywords: alien species, bird trade, environmental suitability, invasion pathway, Taiwan, wildlife trade.

Human activities are moving species beyond their native geographical boundaries and into areas where they do not naturally occur. These species (termed aliens) may, in certain cases, become invasive, and have negative environmental and economic impacts (Clavero \& Garcia-Berthou 2005, Simberloff et al. 2013, Blackburn et al. 2014). These impacts provide a strong impetus to understand invasions over and above the intrinsic interest in studying the determinants of environmental change (Broennimann et al. 2007, Rödder \& Lötters 2009, Lauzeral et al. 2011, Petitpierre et al. 2012, Strubbe et al. 2013). It is now recognized that the invasion process is most usefully analysed as a sequential series of stages (Blackburn et al. 2011): to become an alien invader, a species has to be transported (by humans) from its native range, be introduced into an area in which it does

*Corresponding author.

Email: t.blackburn@ucl.ac.uk not naturally occur, establish a sustainable population, and finally spread out from the location of establishment. A species can only be termed an invasive alien if it succeeds in passing through all of these stages. It follows that to understand invasions, one must understand the entire pathway along which a species moves in the process of changing from native to alien (Blackburn et al. 2009a,b).

An interesting case study of the invasion process relates to alien birds in Taiwan ( $\mathrm{Su}$ et al. 2014). Here, a variety of bird-related cultural activities, such as religious prayer animal release (animals are released for religious reasons, such as to accrue karma), bird contests (including singing competitions) and the keeping of cage-birds (including bird-walking, a social activity in which owners take their caged birds outdoors for fresh air), shape societal demands for bird species. These demands interact with the availability of bird species in trade to shape the species composition of the pet 
bird market in Taiwan (Su et al. 2014) and to determine the characteristics of species that have the opportunity to establish alien populations there. Thus, the bird trade is an important source of introduced species, and at least 70\% of introduced species, and 90\% of established species, have been recorded in the bird markets in Taiwan (Su et al. 2015a). Bird species are more likely to be released (e.g. as prayer animals) or escape if they are more frequently for sale in the Taiwanese pet bird trade and have been sold in the pet market for a longer period (Lee \& Shieh 2005, Su et al. 2015a,b). Establishment success is more likely for large-bodied bird species but is not strongly related to other predicted determinants of success in Taiwan (Su et al. 2015a). Here, we extend this work to the final stage of the invasion pathway, and explore determinants of variation in the extent of spread (geographical range size) of alien bird species in Taiwan.

Previous studies have suggested a number of variables that may be associated with alien bird geographical range sizes. One of the most consistent is the numbers of individuals introduced, or propagule pressure (Duncan et al. 1999, Cassey 2001, Blackburn et al. 2006, 2015, Signorile et al. 2014). It is not clear why species introduced in larger numbers may be able to spread further, but it is possibly because they are less likely to suffer genetic effects arising from a population bottleneck, and are more likely to have individuals with appropriate adaptations to allow spread introduced into the new location (McCauley 1991, Blackburn et al. 2015). Propagule pressure is likely to be high in Taiwan because of prayer animal release and frequent escapes of birds from bird contests, and this should reduce genetic effects arising from population bottlenecks. In addition, a significant number of birds for sale in Taiwan are wild-caught, and such individuals are more likely to survive after liberation than are captive-bred birds (Carrete \& Tella 2008, Cabezas et al. 2012). The length of time since introduction (residence time) may also be related to alien range size because species introduced earlier will have had more time to spread (Duncan et al. 1999, Wilson et al. 2007, Albuquerque et al. 2011).

Species' life history traits are known to be related to native geographical range sizes (Gaston 2003), and may also be related to alien range size if the same processes determine range size in the native and alien environments (Guisan et al.
2014). Species may experience high demographic variance during dispersal in new recipient environments, and traits associated with the ability to overcome such stochasticity may help populations to survive (Blackburn et al. 2009b, Schröder et al. 2009). Larger-bodied species tend to have slower population growth rates and live longer, and so may be more likely to benefit from long-term population persistence under such conditions (Sæther et al. 2004, Blackburn et al. 2009a); they may also be more readily recorded. In addition, species with larger body size also tend to have larger native range size (Gaston 2003) and may as a result be more ecologically generalist. Hence, these species may be able to cope better with different environments. Conversely, small-bodied species tend to have faster population growth rates, and so may spread more rapidly for a given residence time (Duncan et al. 1999, 2001, Mahoney et al. 2015).

Alien geographical range sizes should also be related to features of the recipient environment and to how these interact with the environmental tolerances of the species introduced: spread is not possible if the species cannot survive in the new location. The environmental requirements of many invasive species are conserved in the alien range (Petitpierre et al. 2012, Strubbe et al. 2013), and so the availability of suitable habitats, human interference (Blair 1996, Veech et al. 2011) and climate factors, such as temperature (Hitch \& Leberg 2007, Illán et al. 2014) and precipitation (Tingley et al. 2012, Illán et al. 2014), are likely to be critical to the persistence of alien species (Gammon \& Maurer 2002, Veech et al. 2011). Species traded in Taiwan are more likely to be derived from nearby biogeographical realms (especially the Indo-Malay and Palaearctic; Su et al. 2014), such that the recipient environmental conditions are likely to be similar to those experienced in their native range. A larger native range may imply that species are more tolerant of a wider range of conditions, and hence more likely to encounter suitable environments when introduced (Duncan et al. 2001, Mahoney et al. 2015). Such species may be more likely to succeed in establishment (Croci et al. 2007, Bomford et al. 2009) and to spread across a larger range in the alien location.

Based on these previous studies, we test five predictions for variation in the extent of the alien range sizes of birds in Taiwan. First, we predict that bird species offered more commonly for sale in Taiwan are likely to have larger alien range sizes in 
Taiwan than species rarely offered for sale. Secondly, we predict that species with longer residence times are likely to have larger established range sizes in Taiwan. Thirdly, we predict that large-bodied species will have larger alien range sizes than small-bodied species, as tends to be the case in the native range (although we may see a negative range size-body size relationship in Taiwan if small-bodied species attain their alien ranges more quickly). Fourthly, we predict that alien range size in Taiwan is positively related to native range size, on the assumption that factors that determine native range sizes also influence alien range sizes. Finally, we predict that the extent to which a species can spread in Taiwan is positively related to the environmental match between Taiwan and the species' native range. We also assess whether environmental suitability can distinguish between those alien species that are introduced to Taiwan and succeed and those that fail to establish.

\section{METHODS}

\section{Study area}

The island of Taiwan spans $22^{\circ} \mathrm{N}-25^{\circ} 18^{\prime} \mathrm{N}$ in latitude, and $120^{\circ} 27^{\prime} \mathrm{E}-122^{\circ} \mathrm{E}$ in longitude (Fig. 1).

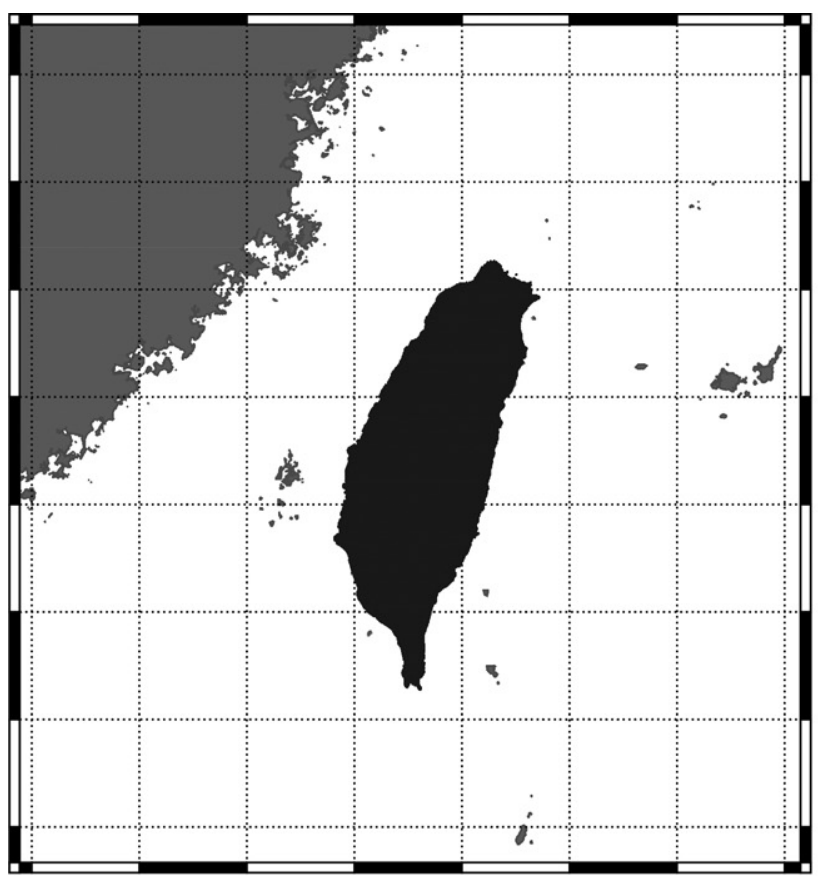

We obtained records of alien species found in the wild in Taiwan from Severinghaus (1999) and a dataset from the Chinese Wild Bird Federation

Figure 1. Location of the study site: the main island of Taiwan. Maps were developed with QGIS (QGIS Development Team 2016).
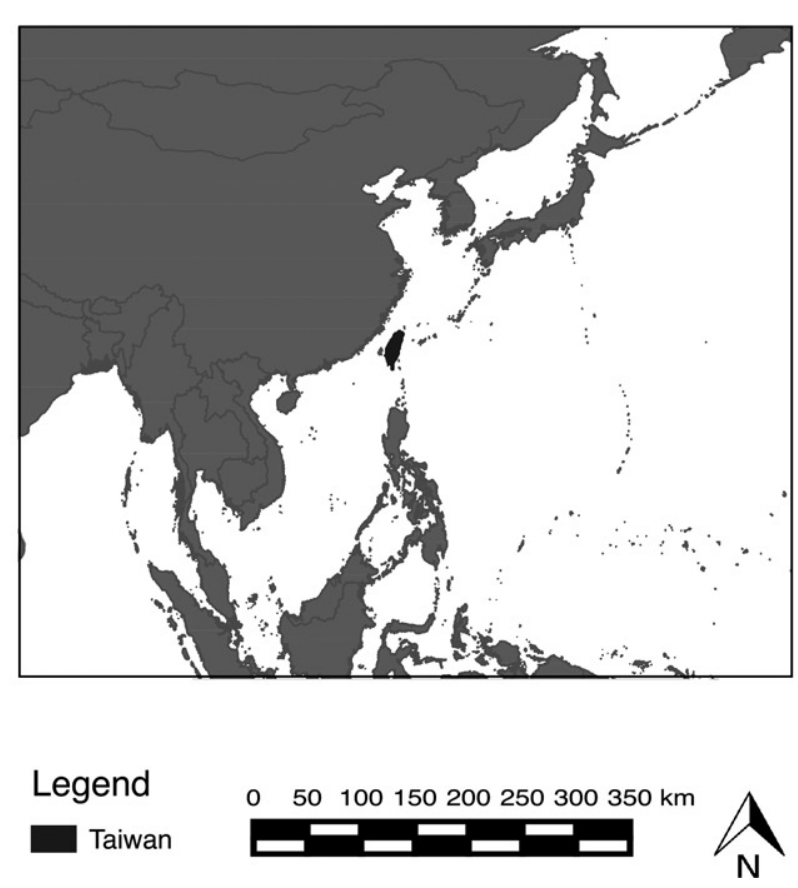
(CWBF) for the years 1972 to 2014. These sources listed 62 alien bird species recorded in the wild that were also found in at least one of three Taiwan pet shop surveys (Chi 1995, Shieh et al. 2006, Su et al. 2015b). Five of the 62 species had fewer than 10 occurrence records from their native

The island has mountainous geography, ranging from sea level to a maximum elevation of $3952 \mathrm{~m}$, includes subtropical (in northern and central regions) and tropical (in the southern region) cliates, with a highland climate in the mountains. $23.6{ }^{\circ} \mathrm{C}$, and annual average precipitation was 2207 mm (Central Water Bureau 2015). The Taiare vagrants, but also includes 25 species and 58 subspecies endemic to the country (Ding et al. 409133 grid cells $(300 \times 300 \mathrm{~m}$, the smallest scale available for the maps used in our study).

\section{Data}

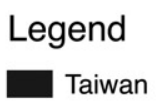 \\ Legend \\ Taiwan}


ranges: one Critically Endangered species Cacatua sulphurea, two Vulnerable species Cacatua moluccensis and Padda oryzivora, one Near Threatened species Cacatua goffiniana, and one Least Concern species Eos bornea (IUCN 2015). This leads to small sample sizes in the environmental modelling algorithm (Wisz et al. 2008), so these five species were removed from the environmental suitability analysis. Hence, the total sample size was 57 .

Twenty-eight of these 57 species are not classified as established or potentially established (see below), and therefore were considered in the analysis as failed introductions. A total of 29 species may be established in the wild, according to the Bird Checklist Taiwan (2011-14). We assigned these to one of two groups: Established: alien species that have had stable breeding records for more than 10 consecutive years in the wild $(n=15)$; and Potentially established: alien species with wild breeding records but not for more than 10 years $(n=14)$. All established $(n=15)$ and potentially established $(n=14)$ species were recorded in the pet shop surveys.

For established species, we calculated the current alien range size in Taiwan (2011-13) based on information $(x-y$ coordinates $)$ in the Breeding Bird Survey (BBS) Taiwan (Ko et al. 2013). To estimate alien range size for each of these species, we created a GIS map polygon by buffering around the observed points to $4 \mathrm{~km}$ (the default maximum distance between survey points in a surveyed area), dissolving areas of overlap between observed points, and then summing the total area covered by the resulting distribution. The values were natural log-transformed for analysis (Anderson-Darling normality test: untransformed alien range size, $A=2.48, P<0.001$; log-transformed alien range size, $A=0.65, P=0.06)$. There are no records available for Cyanopica cyana and Streptopelia decaocto from BBS Taiwan, so the final sample size for established species in the range size analysis was 13 .

We obtained the native geographical range $\left(\mathrm{km}^{2}\right)$ for all traded bird species considered to be failed introductions $(n=28)$, potentially established $(n=14)$ and established $(n=13)$ alien species in Taiwan, from data in Orme et al. (2006), modified by removing alien ranges incorrectly included in some native ranges (Dyer et al. 2016). The data do not include the native range of Amandava subflava; instead, we obtained these from the IUCN Red List (IUCN 2015). The total native range polygons were converted into equal area grids using a Behrmann projection with a cell size of $96.3 \times 96.3 \mathrm{~km}$ (Orme et al. 2006). Native range size was estimated by summing the areas of the grid cells in which species occurred. The values were natural log-transformed for analysis (Anderson-Darling normality test: untransformed native range size, $A=2.37, P<0.001$; log-transformed native range size, $A=0.63, P=0.07$ ).

We recorded residence time for each established species as the number of years since it was first recorded in the wild in the CWBF database (1972-2014). The earliest recorded introduced species in the CWBF database is Columba livia (1972; we used the observation records based on the CWBF database, although the species has certainly been present for much longer, since at least 1840, according to the National Museum of Nature Science, Taiwan). The most recently introduced species are Cyanopica cyanus and Sturnus malabaricus (both in 1998). We obtained information on body mass (g) for established species $(n=13)$ from Olson et al. (2009). For established species, we also recorded the number of birds recorded for sale in the survey of Taiwanese pet shops ( $\mathrm{Su}$ et al. 2015b). The values of body mass and the numbers of birds for sale were natural logtransformed for analysis.

The environmental suitability analyses were based on eight explanatory variables. We removed variables that were highly correlated and chose variables based on their potential biological significance. Hence the selected environment matching variables included: global habitat cover (ESA Climate Change Initiative - Land Cover project 2014), annual maximum green vegetation fraction (MGVF; Broxton et al. 2014) and accessibility (travel time to access closest city or areas of the population greater than 50 000; Nelson 2008). The climate variables included: annual mean temperature $\left({ }^{\circ} \mathrm{C}\right)$, annual temperature range $\left({ }^{\circ} \mathrm{C}\right)$, mean temperature of coldest quarter $\left({ }^{\circ} \mathrm{C}\right)$, annual precipitation $(\mathrm{mm})$ and precipitation of driest quarter (mm) (Hijmans et al. 2005, WorldClim 2015).

\section{Data analysis}

All analyses were performed in $\mathrm{R}$ (version 3.0.3, R Core Development Team 2014), and species range maps were developed with ARCGIS 10.2 (ESRI 2011). 
We tested for phylogenetic correlation in alien range size in Taiwan by calculating variance components on the taxonomic levels of family and genus. The established species derived from only Psittaciformes and Columbiformes, and therefore we did not test for phylogenetic effects at the order level. As the test detected no variance nested at these levels, we used generalized linear models (function $\mathrm{glm}$ ) for subsequent tests related to alien range sizes in Taiwan.

We compared the alien range size of the established species in Taiwan $(n=13)$ with native range size, residence time, body mass, the numbers of birds for sale and environmental suitability (see below) in Taiwan in univariate models. To find the most likely multivariate model for these variables, we used a recursive feature elimination approach, and model averaging from a full model including all five predictors, carried out in $\mathrm{R}$. The feature elimination approach removed variables with a low $t$-statistic using cross-validation as the sampling method, implemented using the function $r f e$ in the caret $\mathrm{R}$ package (Kuhn 2015). To identify the best model, the dredge and model.avg functions in the R package MuMIn (Barton 2015) were used to fit all possible models from the predictor variables (32 models in total, including the null model). We also calculated Akaike weights and variable importance (the sum of the Akaike weights across all models including that variable) based on Akaike information criterion corrected for small sample sizes (AICc).

To assess whether environmental suitability is a determinant of establishment success, we calibrated an environmental match model using MaxEnt (maximum entropy modelling, version 3.3.3k; Phillips et al. 2006). We compared established $(n=15)$, potentially established $(n=14)$ and failed introductions $(n=28)$. First, we created an index of environmental suitability in Taiwan for each of the tested alien species. To do this, we obtained occurrence records within the species' native range from GBIF (GBIF.org 2015), using records of human observations, specimen records and machine observations (such as remote sensor camera records). To reduce sampling bias, duplicated observations of the same species were removed by setting MaxEnt to 'remove duplicate presence records'; thus the records also retained only one occurrence in a single grid cell $(300 \times 300 \mathrm{~m}$, see below and Supporting Information Appendix S1). We calibrated the MaxEnt model in the species' native range using presenceonly data with the environmental explanatory variables described above, and then projected the environmental requirements identified from the native range to Taiwan for each of the tested species (with grid cell size $300 \times 300 \mathrm{~m}$ ). For each species, modelling was performed using 10-fold cross-validation resampling to evaluate the model performance. The performance of predictive models was assessed using the rank-based AUC score (Fielding \& Bell 1997). AUC is the area under the receiver operating characteristic curve, which indicates the probability that a randomly selected presence location is ranked more highly than a randomly selected background location (Phillips et al. 2006, Phillips \& Dudík 2008).

For each species, the model derived from the native range gave an estimated relative probability of presence ranging from 0 to 1 for each grid cell in Taiwan. These values can also be taken to represent environmental suitability (Phillips et al. 2006). As species have different environmental requirements, there was a unique probability distribution model for each species. We used the median value of the probability for each of the species as an index of environmental suitability for Taiwan. These values were logit-transformed prior to analysis. The proportion of suitable areas in Taiwan for each of the tested species was also calculated for analysis. We used a 10\% omission rate for each of the tested species to define the minimum probability of suitable areas in Taiwan. Areas were considered to be suitable when the probability was above the threshold. As the proportion of suitable areas was highly correlated with the median value of the probability $\left(r^{2}=0.85\right)$, we focused on the latter as the index of environmental suitability.

To test whether environmental suitability was associated with establishment success of bird species in the pet trade market, we compared established $(n=15)$, potentially established $(n=14)$ and failed introductions $(n=28)$ in terms of the environmental suitability index. We tested for phylogenetic correlation among species in establishment success (i.e. established or potentially established) in Taiwan, by calculating variance components on the taxonomic levels of order, family and genus. The family level constituted $85.84 \%$ of the variation, and $14.15 \%$ was found at the genus level. No variance was found nested at order level. 
We used generalized linear mixed-effects models (function glmer in the lme 4 package in R; Bates et al. 2015) to fit a binary dependent variable, i.e. whether species succeeded in establishment (established or potentially established), with binomial errors, and family and genus fitted as nested random effects to control for the phylogenetic association among species in the analysis.

We used the same methods to compare established and potentially established species in terms of environmental suitability. Variance was only found at the taxonomic level of family. Therefore, we used a binary dependent variable (whether potentially established and established species differed in terms of environmental suitability) and fitted family as the random effect to control phylogenetic association for potentially established and established species. Figures 2 and 3 were created with the R package ggplot2 (Wickham 2009).

\section{RESULTS}

The maximum entropy model calibrated from the native ranges of the tested species had a good model fit (median AUC score $=0.91$, 1st and 99th percentiles $=0.67,0.98$ ). An AUC score greater than 0.9 is considered to be a very good model, and an AUC between 0.7 and 0.9 is considered to be

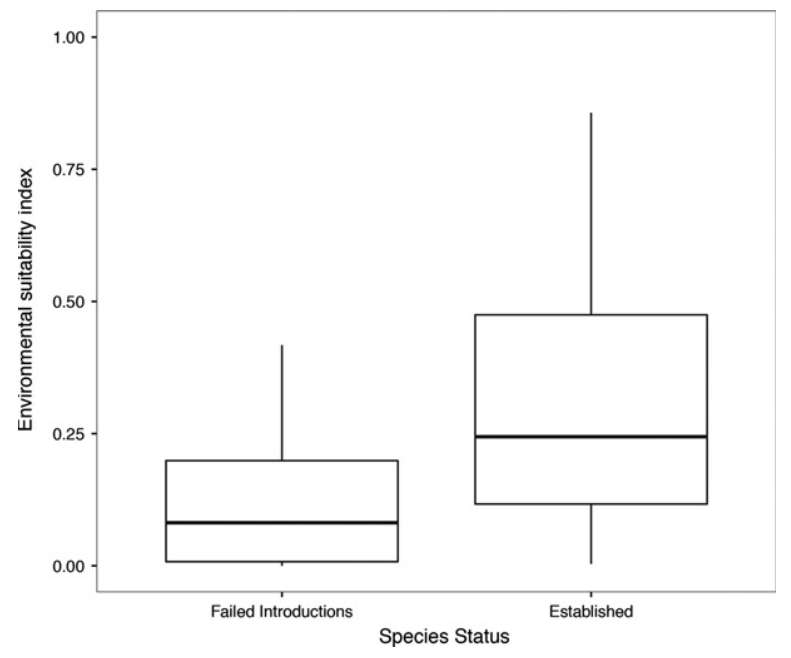

Figure 2. Means of environmental suitability indices in Taiwan for failed introductions $(n=28)$ and established species ( $n=29$, established and potentially established species included). The box represents the interquartile range of the observations in the group, the bold black horizontal line shows the median of the observations and the whiskers indicate the spread of all of the observations in the group.

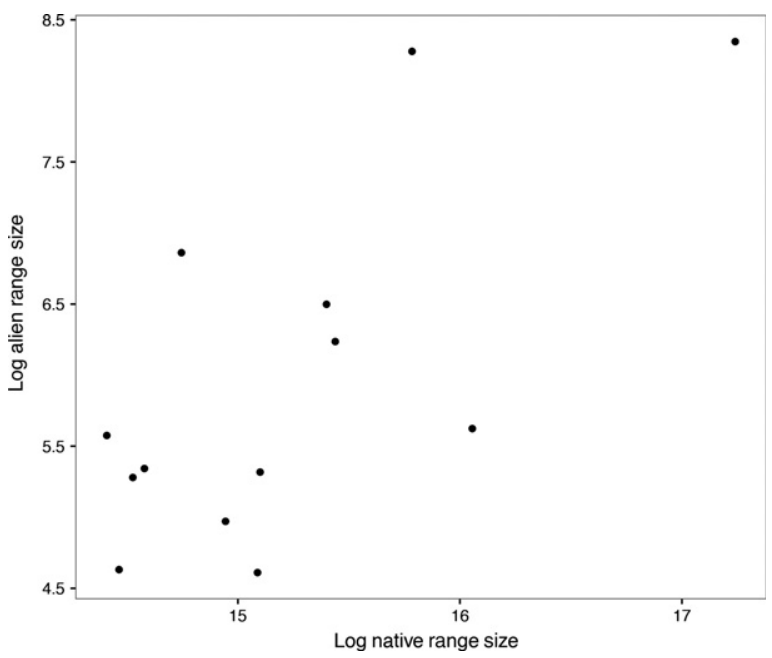

Figure 3. The relationship between log-alien and log-native range size of established species in Taiwan $(n=13)$.

reasonable (Pearce \& Ferrier 2000). The median value of the environmental suitability for all the tested species in Taiwan was 0.15 (1st and 99th percentiles $=2 \times 10^{-8}, 0.91$ ), for failed introductions was 0.08 (1st and 99th percentiles $=1.55 \times 10^{-8}$, $0.9)$ and for established and potentially established species was 0.24 (1st and 99th percentiles $=0.004$, 0.79). A generalized linear mixed-effects model showed that environmental suitability was associated with the establishment success of alien species in Taiwan. Established and potentially established species have significantly higher environmental suitability indices than failed introductions (estimate \pm standard error: $4.84 \pm 1.89, z=2.56, P=0.01$, Fig. 2). However, there was no significant difference between established and potentially established species $(0.4 \pm 2.27, z=0.17, P=0.85)$. We also tested the establishment success of alien species using the proportion of suitable areas. In common with results using the environmental suitability index, these results also showed that establishment success of alien species was positively correlated with the proportion of suitable environments in Taiwan $(3.43 \pm 1.35, z=2.53, P=0.01)$.

Univariate analyses showed that alien bird range sizes in Taiwan were positively associated with native range size (estimate \pm standard error: $1.08 \pm 0.33, t=3.26, \quad P=0.007$, Fig. 3), body mass $(1.72 \pm 0.66, t=2.59, P=0.02)$ and residence time $(0.08 \pm 0.03, t=2.18, P=0.05)$, but showed no relationship with the number of birds for sale $(0.12 \pm 0.15, t=0.82, P=0.42)$ or the 
environmental suitability index $(1.06 \pm 1.43$ $t=0.75, P=0.47$ ). Both cross-validated recursive feature elimination and model average approaches identified native range size and body mass as having strong influences on alien range size in Taiwan (cross-validated adjusted $r^{2}=0.63$ ). Species' alien range sizes in Taiwan tend to be larger for largerbodied species, and for species with larger native ranges (Table 1). Model selection identified 17 models with $\triangle \mathrm{AICc}<10$. The three most likely models with $\triangle \mathrm{AICc}<4$ are given in Table 1 .

\section{DISCUSSION}

The pathway by which species become invasive aliens combines the influences of human-mediated processes and the traits of the species involved. In the early stages of invasion, human preferences and actions are key determinants of which species are transported or introduced. For example, transported alien species are not a random subset of all extant species (Blackburn \& Cassey 2007, Su et al. 2014), locations where species are introduced are not distributed evenly (Blackburn \& Duncan $2001 \mathrm{~b}$ ), and much variation is driven by the types of species chosen by people for translocation and species availability relative to these choices. However, in the later stages of invasion - establishment and spread - species traits matter more. Human activities largely dictate which species are exposed to novel environments, but intrinsic characteristics of these environments and species then influence whether these species subsequently succeed in colonizing them.

For alien bird species introduced to Taiwan, we found that the extent of suitable environments on the island was significantly different between species that failed to establish and those that succeeded in establishing (including those that were potentially established). The environmental suitability index used in the study incorporated anthropogenic influences (e.g. accessibility to human population centres), types of habitats (land cover) and climatic factors (precipitation and temperature variables). Therefore, it seems that species were more likely to establish if these features of the environment in Taiwan were more similar to those in their native ranges. Nevertheless, we still found established and potentially established species with low environmental suitability in Taiwan (e.g. the environmental suitability in Taiwan for Cacatua $a l b a=0.003$ ), and conversely, species that failed to establish despite a very high environmental suitability (e.g. for Serinus canaria $=0.99$ ). Hence, a low environmental suitability to an alien environment is not necessarily a bar to establishment success and, vice versa, a high environmental suitability is not a guarantee of success. It is likely that for some species there are circumstances of the introduction that are more important than environmental suitability. We have shown elsewhere that establishment success in Taiwan was higher for large-bodied bird species ( $\mathrm{Su}$ et al. 2015a), and it is interesting in this regard that the large-bodied C. alba succeeded despite a low environmental suitability, and the small-bodied S. canaria failed despite a high environmental suitability.

Although our results suggest that environmental suitability is important for whether introduced species can succeed in establishing, the occurrence of higher environmental suitability in Taiwan does not appear to matter for the extent of species' alien range sizes: the environmental suitability index was not related to the size of alien range

Table 1. Model-averaged coefficients for predictors of species' alien range in Taiwan, calculated over 17 models, for which the difference of AICc from the best model was less than 10. The three most likely models (M1-M3 with bracketed $\triangle \mathrm{AICc}$ ) included two predictor variables. Akaike weights and AICc for each model are shown. Importance is the sum of the Akaike weights across all models including that variable.

\begin{tabular}{|c|c|c|c|c|c|c|c|c|}
\hline Variables & M1 (0) & M1 (0.89) & M3 (3.48) & Estimate & se & $Z$-value & $\operatorname{Pr}(>|z|)$ & Importance \\
\hline Log native range size & $x$ & $x$ & & 0.97 & 0.30 & 2.82 & 0.005 & 0.85 \\
\hline Log body mass & $x$ & & $x$ & 1.37 & 0.52 & 2.27 & 0.02 & 0.55 \\
\hline Residence time & & & & 0.05 & 0.04 & 1.02 & -0.30 & 0.1 \\
\hline Environmental suitability index & & & -0.08 & 0.23 & 0.25 & 0.32 & 0.08 & \\
\hline Log numbers of birds for sale & & & & 0.04 & 0.11 & 1.02 & 0.30 & 0.04 \\
\hline Intercept & & & & -7.92 & 6.75 & 1.10 & 0.26 & \\
\hline Akaike weight & 0.42 & 0.27 & 0.07 & & & & & \\
\hline $\mathrm{AICc}$ & 44.68 & 45.57 & 48.16 & & & & & \\
\hline
\end{tabular}


sizes in our analyses. It has been shown elsewhere that the number of introduction events (colonization pressure) influences alien bird range size worldwide (Dyer et al. 2016), and this effect may also be more important here. However, information on the number of releases is not available for birds in Taiwan. Bird invasions in Eastern countries are likely to be influenced by the indigenous cage-bird culture, which includes elements such as religious prayer animal release, outdoor bird competitions (including singing competitions) and bird-walking. These activities are likely to be important pathways for traded species to become introduced species. In particular, the practice of prayer animal release moves species beyond their natural barriers and into alien environments on a large scale. Previous studies have found that more than 200 million wild animals are released annually in Taiwan (Environment and Animal Society of Taiwan 2009). A quarter of religious organizations (from several different religions) regularly practise prayer animal release (Environment and Animal Society of Taiwan (EAST) \& Kaohsiung Teacher's Association 2004), and there were 12106 registered temples in Taiwan in 2014 (Ministry of the Interior 2014). In Taipei, around 30\% of residents have participated in prayer animal releases (Severinghaus \& Chi 1999). Both largescale organized animal release and small-scale personal animal release are therefore common and widespread. For these reasons, the abundance of animals in trade, which we have shown elsewhere to be related to the probability of introduction, may be a useful surrogate for the number of release events. Nevertheless, we found no effect of the number of birds for sale on alien range size in Taiwan (Su et al. 2015a), unlike previous studies of alien birds and other species (Gammon \& Maurer 2002, Liu et al. 2014). It is possible that the numbers of birds for sale predicts which bird species are introduced in Taiwan but not how many individuals of those species make it into the wild, and that data on the latter would predict alien range size. Unfortunately, such data are not available.

Species traits appear to have the strongest influences on the alien range size of bird species in Taiwan. We found that alien species with larger body size and larger native geographical range size tended to have larger Taiwanese range sizes. Larger-bodied species tend to have slower population growth rates and to be longer-lived (Peters 1983, Gaston \& Blackburn 2000), characteristics that have been argued to help colonizing species to persist through environmental extremes (Sæther et al. 2004, Blackburn et al. 2009a). Taiwan is a sub-tropical island that usually does not experience periods of extreme temperature or rainfall, but it is hit by regular typhoons (three to five a year, according to Water Resources Agency, Taiwan). Tropical storms have been shown to cause high mortality in wildlife (Ameca y Juárez et al. 2012) and may cause extinctions in small island populations of birds (Martínez-Morales et al. 2009, Şekercioğlu et al. 2012). These extreme events may impact species of different body size differentially, and so explain why larger-bodied species are more likely to establish (Su et al. 2015a) and spread widely in Taiwan.

Positive relationships between native and alien range sizes for alien species, like that shown here for birds in Taiwan, may arise because species with larger native range sizes are likely to be able to exploit a broader range of habitats, or to have wider environmental tolerances (Blackburn \& Duncan 2001a, Croci et al. 2007). However, we tested explicitly for environmental matches between native and alien distribution and found no relationship between the environmental suitability in Taiwan and alien range size.

The univariate analysis produced the expected positive relationship between alien range size and residence time in Taiwan: established bird species present for longer on the island have had longer for their populations to grow and spread, and also more time to adapt to the novel environment (Vellend et al. 2007). They may also have benefitted from longer periods (and hence more instances) of introduction. However, residence time had no relationship with alien range size in the multivariate analyses when the effects of native range size and body size were included. Dyer et al. (2016) found that positive univariate effects of residence time on alien range size at the global scale disappeared in multivariate analysis, although the relationship became significantly negative for reasons that were unclear. It seems that longer residence time is only a small advantage to established bird species, and matters less than other drivers in terms of the extent of their spread, at the time scales considered here.

In conclusion, our results emphasize the importance of environmental similarity between the alien and native ranges of species as a determinant of establishment success, as has been shown in 
other studies. However, environmental matching seems to have less impact on how widely alien bird species spread across Taiwan: instead, this is positively related to the body size and native range size of the species. Thus, importation regulations developed to reduce invasion risk need to find ways to minimize the trade in alien bird species from similar environments because these are more likely to establish viable populations, and with large native range sizes and body sizes, which are more likely subsequently to spread.

We thank William Chi and Bao-Sen Shieh for supplying pet shop surveys. The Chinese Wild Bird Federation provided the database of bird occurrence records in Taiwan. The Endemic Species Research Institute supplied the data from their breeding bird project in Taiwan. David Orme and Valerie Olson supplied data on geographical ranges and body sizes. We also thank Richard Pearson for important advice about niche modelling. We are grateful to Staffan Roos and Dan Chamberlain for the comments that improved the manuscript. This study received financial support from Institute of Zoology, Zoological Society of London.

\section{REFERENCES}

Albuquerque, F.S., de Castro-Díez, P., Rueda, M., Hawkins, B.A. \& Rodríguez, M.Á. 2011. Relationships of climate, residence time, and biogeographical origin with the range sizes and species richness patterns of exotic plants in Great Britain. Plant Ecol. 212: 1901-1911.

Ameca y Juárez, E.I., Mace, G.M., Cowlishaw, G. \& Pettorelli, N. 2012. Natural population die-offs: causes and consequences for terrestrial mammals. Trends Ecol. Evol. 27: 272-277.

Bartoń, K. 2015. MuMIn: Multi-Model Inference. $R$ package version 1.15.1.

Bates, D., Mächler, M., Bolker, B. \& Walker, S. 2015. Fitting linear mixed-effects models using Ime4. J. Stat. Softw. 67: $1-48$.

Blackburn, T.M. \& Cassey, P. 2007. Patterns of nonrandomness in the exotic avifauna of Florida. Divers. Distrib. 13: $519-526$.

Blackburn, T.M. \& Duncan, R.P. 2001a. Determinants of establishment success in introduced birds. Nature 414: 195197.

Blackburn, T.M. \& Duncan, R.P. 2001b. Establishment patterns of exotic birds are constrained by non-random patterns in introduction. J. Biogeogr. 28: 927-939.

Blackburn, T.M., Cassey, P. \& Gaston, K.J. 2006. Variations on a theme: sources of heterogeneity in the form of the interspecific relationship between abundance and distribution. J. Anim. Ecol. 75: 1426-1439.

Blackburn, T.M., Cassey, P. \& Lockwood, J.L. 2009a. The role of species traits in the establishment success of exotic birds. Glob. Change Biol. 15: 2852-2860.
Blackburn, T.M., Lockwood, J.L. \& Cassey, P. 2009b. Avian Invasions: The Ecology and Evolution of Exotic Birds. Oxford: Oxford Avian Biology Series.

Blackburn, T.M., Pyšek, P., Bacher, S., Carlton, J.T., Duncan, R.P., Jarošík, V., Wilson, J.R. \& Richardson, D.M. 2011. A proposed unified framework for biological invasions. Trends Ecol. Evol. 26: 333-339.

Blackburn, T.M., EssI, F., Evans, T., Hulme, P.E., Jeschke, J.M., Kühn, I., Kumschick, S., Marková, Z., Mrugała, A., Nentwig, W., Pergl, J., Pyšek, P., Rabitsch, W., Ricciardi, A., Richardson, D.M., Sendek, A., Vilà, M., Wilson, J.R.U., Winter, M., Genovesi, P., \& Bacher, S. 2014. A unified classification of alien species based on the magnitude of their environmental impacts. PLOS Biol. 12: e1001850.

Blackburn, T.M., Lockwood, J.L. \& Cassey, P. 2015. The influence of numbers on invasion success. Mol. Ecol. 24: 1942-1953.

Blair, R.B. 1996. Land use and Avian species diversity along an urban gradient. Ecol. Appl. 6: 506-519.

Bomford, M., Darbyshire, R.O. \& Randall, L. 2009. Determinants of establishment success for introduced exotic mammals. Wildl. Res. 36: 192.

Broennimann, O., Treier, U.A., Müller-Schärer, H., Thuiller, W., Peterson, A.T. \& Guisan, A. 2007. Evidence of climatic niche shift during biological invasion. Ecol. Lett. 10: 701-709.

Broxton, P.D., Zeng, X., Scheftic, W. \& Troch, P.A. 2014. A MODIS-based global $1-\mathrm{km}$ maximum green vegetation fraction dataset. J. Appl. Meteorol. Climatol. 53: 1996-2004.

Cabezas, S., Carrete, M., Tella, J.L., Marchant, T.A. \& Bortolotti, G.R. 2012. Differences in acute stress responses between wild-caught and captive-bred birds: a physiological mechanism contributing to current avian invasions? Biol. Invasions 15: 521-527.

Carrete, M. \& Tella, J. 2008. Wild-bird trade and exotic invasions: a new link of conservation concern? Front. Ecol. Environ. 6: 207-211.

Cassey, P. 2001. Determining variation in the success of New Zealand land birds. Glob. Ecol. Biogeogr. 10: 161-172.

Central Water Bureau 2015. Climate Monitoring 2014 Annual Report. Taiwan: Central Water Bureau.

Chi, W.L. 1995. An Investigation Report on Pet Bird Trade in Taiwan. Taipei, Taiwan: Green Consumer's Foundation.

Clavero, M. \& Garcia-Berthou, E. 2005. Invasive species are a leading cause of animal extinctions. Trends Ecol. Evol. 20: 110.

Croci, S., Quilliec, P.L. \& Clergeau, P. 2007. Geographical range as predictor of spatial expansion of invading birds. Biodivers. Conserv. 16: 511-524.

Ding, T.-S., Juan, C.-S., Lin, R.-S., Pan, C.-Y., Tsai, Y.-J., Wu, J. \& Yang, Y.-H. 2014. The 2014 CWBF Checklist of the Birds of Taiwan. Taipei: Bird Record Committee, Chinese Wild Bird Federation.

Duncan, R.P., Blackburn, T.M. \& Veltman, C.J. 1999. Determinants of geographical range sizes: a test using introduced New Zealand birds. J. Anim. Ecol. 68: 963-975.

Duncan, R.P., Bomford, M., Forsyth, D.M. \& Conibear, L. 2001. High predictability in introduction outcomes and the geographical range size of introduced Australian birds: a role for climate: bird introductions to Australia. J. Anim. Ecol. 70: 621-632. 
Dyer, E.E., Franks, V., Cassey, P., Collen, B., Cope, R.C., Jones, K.E., Sekercioglu, C.H. \& Blackburn, T.M. 2016. A global analysis of the determinants of alien geographic range size in birds. Glob. Ecol. Biogeogr. 25: 1346-1355.

Environment and Animal Society of Taiwan 2009. The Investigation of Prayer Animal Releases in Taiwan. Taiwan: Environment \& Animal Society of Taiwan and Human Society International.

Environment and Animal Society of Taiwan (EAST) \& Kaohsiung Teacher's Association 2004. The Practices of Prayer Animal Releases Conducted by Religious Organisations in Taiwan. Taiwan: Environment and Animal Society of Taiwan.

ESA Climate Change Initiative - Land Cover project. 2014. Land Cover Map 2010.

ESRI 2011. ArcGIS Desktop. Redlands, CA: Environmental Systems Research Institute.

Fielding, A.H. \& Bell, J.F. 1997. A review of methods for the assessment of prediction errors in conservation presence/ absence models. Environ. Conserv. 24: 38-49.

Forestry Bureau 2010. The Land Cover in Taiwan. Taiwan: Council of Agriculture, Forestry Bureau.

Gammon, D.E. \& Maurer, B.A. 2002. Evidence for nonuniform dispersal in the biological invasions of two naturalized North American bird species. Glob. Ecol. Biogeogr. 11: 155-162.

Gaston, K.J. 2003. The Structure and Dynamics of Geographic Ranges. Oxford: Oxford Series in Ecology and Evolution.

Gaston, K.J. \& Blackburn, T.M. 2000. Pattern and Process in Macroecology. Oxford: Blackwell Science.

GBIF.org. 2015. GBIF Occurrence Download.

Guisan, A., Petitpierre, B., Broennimann, O., Daehler, C. \& Kueffer, C. 2014. Unifying niche shift studies: insights from biological invasions. Trends Ecol. Evol. 29: 260-269.

Hijmans, R.J., Cameron, S.E., Parra, J.L., Jones, P.G. \& Jarvis, A. 2005. Very high resolution interpolated climate surfaces for global land areas. Int. J. Climatol. 25: 19651978.

Hitch, A.T. \& Leberg, P.L. 2007. Breeding distributions of north american bird species moving north as a result of climate change. Conserv. Biol. 21: 534-539.

Illán, J.G., Thomas, C.D., Jones, J.A., Wong, W.-K., Shirley, S.M. \& Betts, M.G. 2014. Precipitation and winter temperature predict long-term range-scale abundance changes in Western North American birds. Glob. Change Biol. 20: 3351-3364.

IUCN. 2015. The IUCN Red List of Threatened Species. Version 2015.1. www.iucnredlist.org (accessed June 2015).

Ko, C.J., Fan, M.W., Jiang, Y.X., Yo, W.J., Lo, Y.Y., Huang, K.W., Lin, R.-S., Cheng, C.-C. \& Lee, P.-F. 2013. 2012 Taiwan Breeding Bird Survey Annual Report. Nantou: Council of Agriculture, Endemic Species Research Institute, Taiwan.

Kuhn, M., Wing, J., Weston, S., Williams, A., Keefer, C., Engelhardt, A., Cooper, T., Mayer, Z., Kenkel, B., the R Core Team, Benesty, M., Lescarbeau, R., Ziem, A., Scrucca, L., Tang, Y. \& Candan, C. 2015. caret: Classification and Regression Training. $\mathrm{R}$ package version 6.0-70. Available at: https://CRAN.R-project.org/package= caret

Lauzeral, C., Leprieur, F., Beauchard, O., Duron, Q., Oberdorff, T. \& Brosse, S. 2011. Identifying climatic niche shifts using coarse-grained occurrence data: a test with nonnative freshwater fish. Glob. Ecol. Biogeogr. 20: 407-414.

Lee, T.W. \& Shieh, B.S. 2005. Pet sales of exotic estrildid birds in relation to the field-records in Taiwan. Endem. Species Res. 7: 1-12.

Liu, X., Li, X., Liu, Z., Tingley, R., Kraus, F., Guo, Z. \& Li, Y. 2014. Congener diversity, topographic heterogeneity and human-assisted dispersal predict spread rates of alien herpetofauna at a global scale. Ecol. Lett. 17: 821-829.

Mahoney, P.J., Beard, K.H., Durso, A.M., Tallian, A.G., Long, A.L., Kindermann, R.J., Nolan, N.E., Kinka, D. \& Mohn, H.E. 2015. Introduction effort, climate matching and species traits as predictors of global establishment success in non-native reptiles. Divers. Distrib. 21: 64-74.

Martínez-Morales, M.A., Cruz, P.C. \& Cuarón, A.D. 2009. Predicted population trends for Cozumel Curassows (Crax rubra griscomi): empirical evidence and predictive models in the face of climate change. J. Field Ornithol. 80: 317-327.

McCauley, D.E. 1991. Genetic consequences of local population extinction and recolonization. Trends Ecol. Evol. 6: 5-8.

Ministry of the Interior 2014. Religion in Taiwan. Taiwan: Ministry of the Interior.

Nelson, A. 2008. Estimated Travel Time to the Nearest City of 50,000 or More People in Year 2000. Ispra: Global Environment Monitoring Unit - Joint Research Centre of the European Commission.

Olson, V.A., Davies, R.G., Orme, C.D.L., Thomas, G.H., Meiri, S., Blackburn, T.M., Gaston, K.J., Owens, I.P. \& Bennett, P.M. 2009. Global biogeography and ecology of body size in birds. Ecol. Lett. 12: 249-259.

Orme, C.D.L., Davies, R.G., Olson, V.A., Thomas, G.H., Ding, T.-S., Rasmussen, P.C., Ridgely, R.S., Stattersfield, A.J., Bennett, P.M., Owens, I.P., Blackburn, T.M. \& Gaston, K.J. 2006. Global patterns of geographic range size in birds. PLoS Biol. 4: e208.

Pearce, J. \& Ferrier, S. 2000. Evaluating the predictive performance of habitat models developed using logistic regression. Ecol. Model. 133: 225-245.

Peters, R.H. 1983. The Ecological Implications of Body Size. Cambridge: Cambridge University Press.

Petitpierre, B., Kueffer, C., Broennimann, O., Randin, C., Daehler, C. \& Guisan, A. 2012. Climatic niche shifts are rare among terrestrial plant invaders. Science 335: 1344-1348.

Phillips, S.J. \& Dudík, M. 2008. Modeling of species distributions with Maxent: new extensions and a comprehensive evaluation. Ecography 31: 161-175.

Phillips, S.J., Anderson, R.P. \& Schapire, R.E. 2006. Maximum entropy modeling of species geographic distributions. Ecol. Model. 190: 231-259.

QGIS Development Team. 2016. QGIS Geographic Information System. Open Source Geospatial Foundation Project.

R Core Team. 2014. R: A Language and Environment for Statistical Computing. Vienna: R Foundation for Statistical Computing.

Rödder, D. \& Lötters, S. 2009. Niche shift versus niche conservatism? Climatic characteristics of the native and invasive ranges of the Mediterranean house gecko (Hemidactylus turcicus). Glob. Ecol. Biogeogr. 18: 674-687.

Sæther, B., Engen, S., Pape Møller, A., Weimerskirch, H., Visser, M.E., Fiedler, W., Matthysen, E., Lambrechts, 
M.M., Badyaev, A.V., Becker, P.H., Brommer, J.E., Bukacinski, D., Bukacinski, M., Christensen, H., Dickinson, J., du Feu, C., Gehlbach, F.R., Heg, D., Hötker, H., Merilä, J., Nielsen, J.T., Rendell, W., Robertson, R.J., Thomson, D.L., Török,, J., \& Van Hecke, P. 2004. Life-history variation predicts the effects of demographic stochasticity on avian population dynamics. Am. Nat. 164: 793-802.

Schröder, A., Nilsson, K.A., Persson, L., van Kooten, T. \& Reichstein, B. 2009. Invasion success depends on invader body size in a size-structured mixed predation-competition community. J. Anim. Ecol. 78: 1152-1162.

Şekercioğlu, Ç.H., Primack, R.B. \& Wormworth, J. 2012. The effects of climate change on tropical birds. Biol. Conserv. 148: 1-18.

Severinghaus, L.L. 1999. Exotic birds in Taiwan. Wild Birds 7: 45-58.

Severinghaus, L.L. \& Chi, L. 1999. Prayer animal release in Taiwan. Biol. Conserv. 89: 301-304.

Shieh, B., Lin, Y., Lee, T., Chang, C. \& Cheng, K. 2006. Pet trade as sources of introduced bird species in Taiwan. Taiwania 51: 81-86.

Signorile, A.L., Wang, J., Lurz, P.W.W., Bertolino, S., Carbone, C. \& Reuman, D.C. 2014. Do founder size, genetic diversity and structure influence rates of expansion of North American grey squirrels in Europe? Divers. Distrib. 20: 918-930.

Simberloff, D., Martin, J.-L., Genovesi, P., Maris, V., Wardle, D.A., Aronson, J., Courchamp, F., Galil, B., GarcíaBerthou, E., Pascal, M., Pyšek, P., Sousa, R., Tabacchi, E. \& Vilà, M. 2013. Impacts of biological invasions: what's what and the way forward. Trends Ecol. Evol. 28: 58-66.

Strubbe, D., Broennimann, O., Chiron, F. \& Matthysen, E. 2013. niche conservatism in non-native birds in Europe: niche unfilling rather than niche expansion: niche conservatism among non-native birds. Glob. Ecol. Biogeogr. 22: 962-970.

Su, S., Cassey, P. \& Blackburn, T.M. 2014. Patterns of nonrandomness in the composition and characteristics of the Taiwanese bird trade. Biol. Invasions 16: 2563-2575.

Su, S., Cassey, P. \& Blackburn, T.M. 2015a. The wildlife pet trade as a driver of introduction and establishment in alien birds in Taiwan. Biol. Invasions 18: 215-229.
Su, S., Cassey, P., Vall-llosera, M. \& Blackburn, T.M. 2015b. Going cheap: determinants of bird price in the Taiwanese pet market. PLOS ONE 10: e0127482.

Tingley, M.W., Koo, M.S., Moritz, C., Rush, A.C. \& Beissinger, S.R. 2012. The push and pull of climate change causes heterogeneous shifts in avian elevational ranges. Glob. Change Biol. 18: 3279-3290.

Veech, J.A., Small, M.F. \& Baccus, J.T. 2011. The effect of habitat on the range expansion of a native and an introduced bird species. J. Biogeogr. 38: 69-77.

Vellend, M., Harmon, L.J., Lockwood, J.L., Mayfield, M.M., Hughes, A.R., Wares, J.P. \& Sax, D.F. 2007. Effects of exotic species on evolutionary diversification. Trends Ecol. Evol. 22: 481-488.

Wickham, H. 2009. Ggplot2: Elegant Graphics for Data Analysis. New York: Springer.

Wilson, J.R.U., Richardson, D.M., Rouget, M., Procheş, Ş., Amis, M.A., Henderson, L. \& Thuiller, W. 2007. Residence time and potential range: crucial considerations in modelling plant invasions. Divers. Distrib. 13: 11-22.

Wisz, M.S., Hijmans, R.J., Li, J., Peterson, A.T., Graham, C.H., Guisan, A., NCEAS Predicting Species Distribution Working Group 2008. Effects of sample size on the performance of species distribution models. Divers. Distrib. 14: 763-773.

WorldClim. 2015. Global Climate Data. http://www.world clim.org/about. Accessed July 2015.

Received 25 April 2016; revision accepted 1 October 2016. Associate Editor: Staffan Roos.

\section{SUPPORTING INFORMATION}

Additional Supporting Information may be found in the online version of this article:

Appendix S1. Species list and variables used in the analysis. 